\title{
Pemisahan Suara Manusia Berdasarkan Jenis Kelamin Menggunakan Fast Fourier Transform (FFT)
}

\author{
Lela Sari Kristina ${ }^{1}$, Gita Fadila Fitriana ${ }^{2}$, Agi Prasetiadi ${ }^{3}$ \\ ${ }^{1,2}$ Institut Teknologi Telkom Purwokerto; Jl. DI. Panjaitan No.128 Purwokerto 53147, \\ Telp(0281)641629 Fax. (0281)641630 \\ ${ }^{3}$ Teknik Informatika, Institut Teknologi Telkom Purwokerto \\ e-mail: *116102127@ittelkom-pwt.ac.id, ${ }^{1}$ gita@ittelkom-pwt.ac.id, ${ }^{3}$ agi@ittelkom-pwt.ac.id
}

\begin{abstract}
Abstrak
Suara merupakan salah satu ciri yang dimiliki oleh manusia. Salah satu kemampuan manusia untuk melakukan identifikasi terhadap seseorang dengan cara melihat dan mendengar. Melalui kemampuan tersebut seseorang dapat membedakan jenis kelamin dengan mudah, berdasarkan kategori fisik dan suara. Suara yang sebelumnya dapat dikenali dengan mudah oleh manusia, untuk saat ini dapat dikenali pula oleh komputer, yang bertujuan untuk memisahkan suara berdasar jenis kelamin. Hasil akhir dari penelitian ini adalah megetahui rata-rata error dari objek data yang sudah di inputkan dengan Algoritme yang digunakan dalam penelitian ini adalah Fast Fourier Transform. Hasil dari proses implementasi dari Algoritme Fast Fourier Transform menujukan besar atau tidaknya rata-rata error suara yang dipengaruhi tinggi atau rendahnya amplitudo dari suara yang sedang diuji dan dari hasil yang didapatkan rata-rata error amplitudo suara Perempuan lebih rendah dari pada rata-rata error amplitudo suara Laki-laki. Dari dua sumber suara manusia yang digunakan menghasilkan rata-rata error terendah pada cluster ke-7 pada suara Perempuan 3 dengan hasil rata-rata error 132.840, sementara pada hasil uji coba yang dilakukan dengan 3 sumber suara menghasil rata-rata error terendah pada cluster ke-3 pada suara Perempuan 3 dengan hasil rata-rata error 212.976, dan pada empat sumber suara yang digunakan menghasilkan rata-rata error terendah pada cluster ke-3 pada suara Mela dengan hasil rata-rata error 217.462 .
\end{abstract}

Kata kunci-Algoritme, Amplitudo, Fast Fourier Transform, Implementasi, Suara.

\begin{abstract}
Voice is one of the characteristics possessed by humans. One of the human abilities to identify someone by seeing and hearing. Through this ability one can easily distinguish gender, based on physical and voice categories. voices that previously can be recognized easily by humans, for now can also be recognized by computers, which aims to separate sounds based on gender. The final result of this research is to know the average error of data objects that have been inputted with the algorithm used in this study is the Fast Fourier Transform. The results of the implementation process of the Fast Fourier Transform Algorithm show whether or not the average sound error is influenced by the high or low amplitude of the sound being tested and from the results obtained the average error amplitude of the female voice is lower than the average error amplitude. Male voice. Of the two sources of human voices used, the lowest average error was produced in the 7th cluster for Female 3 votes with an average error result of 132.840, while the results of trials conducted with 3 sound sources resulted in the lowest average error in the second cluster. -3 for Female 3 votes with an average error result of 212,976, and for the four sound sources used it produces the lowest average error in the 3rd cluster on Mela's voice with an average error result of 217,462.
\end{abstract}

Keywords - Algorithm, Amplitude, Fast Fourier Transform, Implementation, Voice. 


\section{PENDAHULUAN}

$\mathrm{M}$ anusia merupakan makhluk sosial yang membutuhkan komunikasi dengan sesamanya dalam kehidupan sehari-hari untuk mendukung kebutuhan hidup mereka. Suara ialah salah satu media komunikasi yang paling sering serta umum digunakan oleh manusia. Manusia bisa memproduksi suaranya dengan mudah tanpa membutuhkan tenaga yang besar. Manusia pula dapat mengendalikan serta mengatur suara mereka yang disebut bernyanyi, sehingga menciptakan keluaran suara yang baik serta bagus. Tidak hanya itu, setiap manusia memiliki wujud suara ataupun kepribadian suara yang berbeda-beda, sehingga suara bisa dibedakan dengan cara didengarkan ataupun dengan memakai metode tertentu [1].

Perkembangan teknologi dewasa ini semakin cepat membuktikan kemajuannya, perkembangan teknologi sesuatu yang tidak dapat kita jauhi dalam kehidupan ini, sebab kemajuan teknologi akan berjalan sesuai dengan kemajuan ilmu pengetahuan. Khususnya dalam bidang teknologi penduduk telah menikmati. Manusia tidak lepas dari adanya teknologi, artinya kalau teknologi merupakan metode mudah dalam tiap aktivitas manusia. Maka dari itu dengan berkembangnya teknologi permasalahan akan mudah terselesaikan [2].

Pada kemajuan teknologi yang akan berjalan sesuai dengan kemajuan ilmu pengetahuan. Setiap inovasi diciptakan untuk memberikan manfaat positif bagi kehidupan manusia. Memberikan banyak kemudahan, serta sebagai cara baru dalam melakukan aktifitas manusia. Khusus dalam bidang teknologi masyarakat sudah menikmati banyak manfaat yang dibawa oleh inovasi-inovasi yang telah dihasilkan dalam beberapa tahun terakhir ini [3].

Perkembangan dalam hal mengidentifikasi suara belum banyak diterapkan, dikarenakan belum banyak orang yang mengetahui bagaimana suara itu bisa diidentifikasi berdasarkan suara yang dimasukan dan akan tampil sinyal suara yang dihasilkan. Suara yang dikeluarkan manusia merupakan salah satu media yang utama untuk berkomunikasi dengan sesama manusia selain media komunikasi yang lain seperti isyarat dan tulisan. Fast Fourier Transform (FFT) adalah suatu Algoritme untuk menghitung transformasi Fourier diskrit (Discrete Fourier Transform) dengan cepat dan efisien. Dalam melakukan teknik FFT ini terdapat teknik decimation in time (DIT) dan decimation in frequency (DIF) [4]. Proses identifikasi merupakan salah satu bidang teknologi yang sedang banyak dikembangkan, alasannya sendiri bermacam-macam beberapa diantara adalah untuk pengembangan sistem keamanan, marketing, Human and Computer Interaction (HCI), autentikasi biometrik, dan lain-lainnya.

Salah satu cara dalam proses identifikasi seseorang adalah dengan cara mengidentifikasi ciri biometriknya (identitas manusia) yang dilakukan karena fitur-fitur yang terdapat didalamnya bersifat unik dalam artian berbeda antara setiap manusia, salah satu contohnya adalah suara [5]. Format suara yang digunakan pada penelitian ini menggunakan MP3, MP3 sendiri merupakan format kompresi audio yang dikembangkan oleh Moving Picture Experts Group (MPEG). Format file ini menggunakan Layer 3 kompresi audio yang secara umum digunakan untuk menyimpan file - file music dan audiobooks dalam hard drive. Format file MP3 mampu memberikan kualitas suara yang mendekati kualitas CD stereo dengan 16-bit. Kualitas suara file MP3 tergantung pada sebagian besar bit rate yang digunakan untuk kompresi [6].

Berdasarkan latar belakang tersebut, penulis bermaksud mengajukan sebuah penelitian mengenai sistem untuk memisahkan suara laki-laki dan suara perempuan. Karena belum adanya penelitian yang meneliti meggenai pemisahan suara manusia berdasarkan jenis kelamin. Sehingga kelebihan yang ingin ditunjukan yaitu dapat mengenali suara dan memisah suara lakilaki dan perempuan, sehingga jika ada 2 orang atau lebih yang berbicara secara bersamaan kita dapat mengetahui apa yang mereka bicarakan dengan memisahkan suara mereka dan dapat kita dengarkan kembali sehingga dapat juga membantu tunawicara agar dapat membedakan suara

Lela Sari Kristina, et., al [Pemisahan Suara Manusia Berdasarkan Jenis Kelamin Menggunakan Fast Fourier Transform (FFT)] 
orang yang berada disekitar mereka, tunawicara itu sendiri merupakan seseorang yang tidak dapat berkomunikasi dengan normal. Dalam berinteraksi tunawicara lebih memilih menggunakan bahasa isyarat dan tentu ini menyebabkan terjadinya kesenjangan dan sulitnya melakukan penyebaran informasi [7]. Untuk mengatasi masalah tersebut diperlukan suatu sistem analisis yang bertujuan untuk memudahkan interaksi antara sesama tunawicara dengan orang normal.

\section{DASAR TEORI}

1. Suara

Suara adalah fenomena fisik yang dihasilkan oleh getaran benda atau getaran suatu benda yang berupa sinyal analog dengan amplitudo yang berubah secara kontinyu terhadap waktu, suara berhubungan erat dengan rasa "mendengar". Suara atau bunyi biasanya merambat melalui udara. Suara atau bunyi tidak bisa merambat melalui ruang hampa.

Suara dihasilkan oleh getaran suatu benda. Selama bergetar, perbedaan tekanan terjadi di udara sekitarnya. Pola osilasi yang terjadi dinamakan sebagai "Gelombang". Manusia mendengar bunyi saat gelombang bunyi, yaitu getaran di udara atau medium lain, sampai ke gendang telinga manusia. Batas frekuensi bunyi yang dapat didengar oleh telinga manusiakira-kira dari $20 \mathrm{~Hz}$ sampai $20 \mathrm{kHz}$ pada amplitudo umum dengan berbagai variasi dalam kurva responsnya. Suara di atas $20 \mathrm{kHz}$ disebut ultrasonik dan di bawah $20 \mathrm{~Hz}$ disebut infrasonik [8].

2. Pengenalan Suara

Speech recognition atau pengenalan suara adalah sebuah proses untuk mengenali atau menerjemahkan huruf, kata, atau kalimat yang diucapkan oleh manusia secara langsung atau melalui suara rekaman yang dapat dimengerti oleh mesin misalnya komputer dan smart phone [9].

3. Frekuensi Manusia

Umumnya manusia memiliki kemampuan untuk mendengar suara pada rentang frekuensi 20 - 20.000 Hertz (Hz). Hertz adalah jumlah getaran suara per detik pada telinga. Jika suatu suara memiliki frekuensi tinggi, maka suara tersebut akan bergetar lebih cepat. Begitu pula sebaliknya, jika frekuensi suara rendah, maka getarannya pun juga akan melambat [10]. Seluruh suara di alam yang tidak jatuh pada rentang tersebut tidak akan dapat didengar oleh telinga manusia. Sedangkan frekuensi di komputer 44.100 karena samplingnya 2 kali lebih besar.

4. Teorema Nyquist

Teknik sampling klasik didasarkan atas teorema Nyquist-Shannon yang menyatakan bahwa sinyal analog harus disampling dengan frekuensi sampling sekurang-kurangnya dua kali frekuensi tertinggi dari sinyal yang disampling agar dapat direkonstruksi [11].

5. Fast Fourier Transform

Fast Fourier Trasform (FFT) adalah teknik perhitungan yang cepat dengan memanfaatkan sifat periodikal dari transformasi fourier yang berfungsi merubah dari domain waktu ke domain frekuensi. Teori ini ditemukan oleh J.W Cooley dan J.W. Tukey pada tahun 1960. Fast Fourier Transformation atau transformasi Fourier cepat, merupakan proses lanjutan dari DFT (Discrete Fourier Transformation). DFT adalah prosedur matematis yang digunakan untuk menentukan harmonik, atau frekuensi serta isi dari urutan sinyal diskrit.

Dalam proses fast fourier transform akan menghasilkan dua buah nilai yaitu nilai real dan nilai imajiner. Dan untuk proses selanjutnya dibutuhkan nilai real saja untuk itu diperlukan proses mutlak log [12]. 


\section{Invers Fast Fourier Transform}

Metode IFFT (Inverse Fast Fourier Transform) adalah kebalikan dari FFT (Fast Fourier Transform), dimana FFT merupakan transformasi sinyal dari domain frekuensi ke domain waktu dengan menggunakan IDFT (Inverse Discrete Fourier Transform) [13].

7. Filtering

Filter merupakan rangkaian yang berfungsi untuk melewatkan sinyal frekuensi yang diinginkan dan menahan sinyal frekuensi yang tidak diinginkan. Filter dapat diklasifikasikan menjadi dua yaitu filter analog dan digital. Filter analog dirancang untuk memproses sinyal analog, sedang filter digital memproses sinyal analog dengan menggunakan teknik digital [14].

8. Mean Absolute Error

Dalam mengevaluasi kinerja Algoritme Fast Fourier Tansform (FFT), pada pemrosesan untuk mengetahui rata-rata error amplitudo suara yang diuji menggunakan Mean Absolute Error (MAE) yang merupakan salah satu metode yang digunakan untuk mengukur tingkat keakuratan model peramalan. Hasil Mean Absolute Error menunjukkan nilai rata-rata kesalahan mutlak atau absolut dari nilai sebenarnya dengan nilai peramalan [15].

9. Phyton

Python merupakan bahasa pemrograman tingkat tinggi yang ditemukan oleh Guido van Rossum. Python banyak digunakan untuk membuat berbagai macam program, seperti program CLI, Program GUI (desktop), Aplikasi Mobile, Web, IoT, Game, Program untuk Hacking, dan sebagainya. Python juga dikenal dengan bahasa pemrograman yang mudah dipelajari, karena struktur sintaknya rapi dan mudah dipahami [16].

\section{METODE PENELITIAN}

Sampel penelitian yang digunakan pada penelitian ini yaitu pada fase percobaan menggunakan objek data suara dengan 3 suara hewan yaitu suara anjing, kucing, burung dan pada objek data suara manusia yaitu suara laki-laki dan perempuan. Pada objek data suara hewan didapatkan dari youtube yang berformat MP4 kemudian file diconvert menjadi MP3. Adapun objek data suara manusia yaitu suara laki-laki dan perempuan yang didapatkan dari suara orang-orang terdekat penulis sendiri dan ada beberapa suara yang didapatkan dari youtube.

Pada Tahapan pengolahan data, yang dimulai dari pengambilan objek data kemudian data di gabungkan menjadi 2, 3 dan 4 objek data menggunakan Fast Fourier Transform, setelah digabungan objek data dipisahkan kembali menggunakan Inverse Fast Fourier Transform kemudian melakukan Preprocessing data untuk memotong suara setiap per1 detik, dan pada pengujian objek data dengan menggunakan Mean Absolute Error untuk mencari rata-rata error dari sebuah objek data yang sedang di uji.

Dalam mengevaluasi kinerja Algoritme Fast Fourier Tansform (FFT), pada pemrosesan untuk analisis pengujian dengan mengetahui rata-rata error suara yang diuji menggunakan Mean Absolute Error (MAE) yang merupakan metode untuk mengukur tingkat keakuratan suatu model peramalan. Nilai MAE merepresentasikan rata - rata kesalahan (error) absolut antara hasil peramalan dengan nilai sebenarnya. 


\section{HASIL DAN PEMBAHASAN}

1. Hasil Uji

Pemisahan Suara Manusia

1.1. Dua Sumber Suara

Laki-laki durasi 10 detik dan Perempuan durasi 10 detik.

Berikut merupakan domain frekuensi pada objek data suara Laki-laki dengan durasi 10 detik dan Perempuan dengan durasi 10 detik.

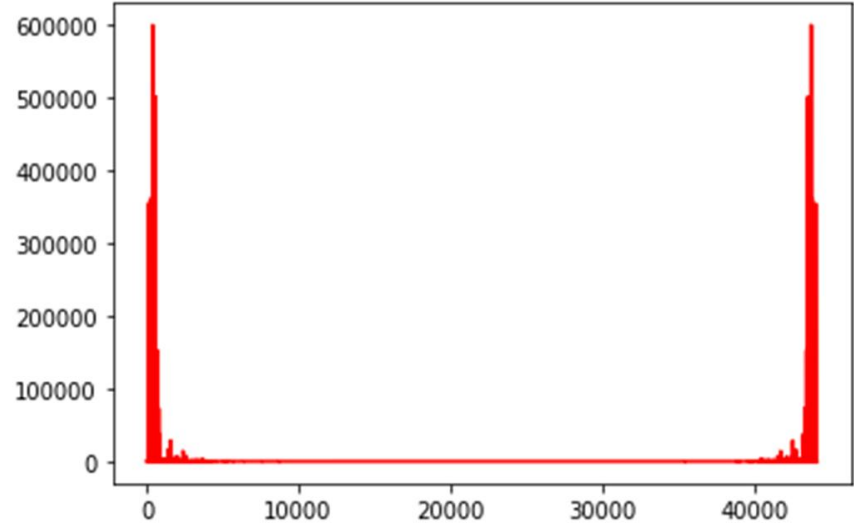

Gambar 1. Domain Frekuensi Suara Laki-laki Durasi 10 Detik + Perempuan Durasi 10 Detik

\subsection{Tiga Sumber Suara}

Laki-laki 2, Perempuan 2 dan Perempuan 3.

Berikut merupakan domain frekuensi pada objek data suara Laki-laki 2, Perempuan 2 dan Perempuan 3.

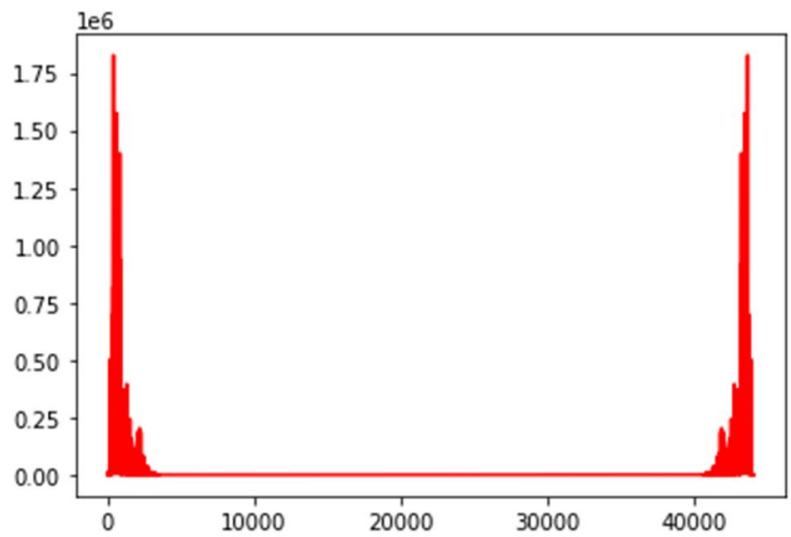

Gambar 2. Domain Frekuensi Suara Laki-laki 2 + Perempuan 2 + Perempuan 3

\subsection{Empat Sumber Suara}

Suara Elin, Mela, Kiki dan Olvy

Berikut merupakan domain frekuensi pada objek data suara Elin, Mela, Kiki dan Olvy. 


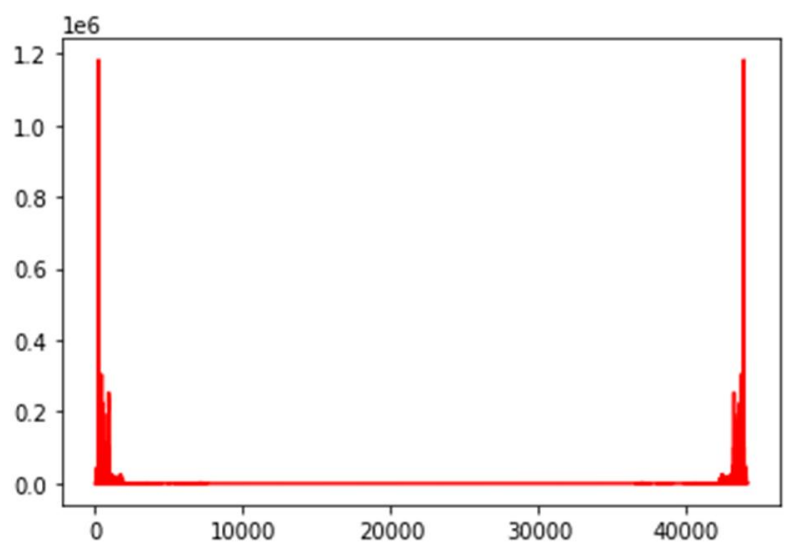

Gambar 3. Domain Frekuensi Suara Elin + Mela + Kiki + Olvy

\section{KESIMPULAN}

1. Rata-rata error suara Laki-laki sebesar 2675.113 lebih tinggi dari pada suara Perempuan sebesar 132.840. Namun, suara perempuan lebih jelas terfilter di telinga dibanding suara laki-laki.

2. Suara yang lebih besar tidak menjamin frekuensi dan amplitudo dideteksi oleh komputer.

3. Objek data yang diinputkan menggunakan durasi yang pendek.

4. Dengan algoritme Fast Fourier Transform lebih mudah untuk memisahkan didomain frekuensi

\section{SARAN}

Adapun saran yang diberikan pada penelitian ini yaitu penelitian selanjutnya diharapkan bisa mendapatkan rata-rata error suara agar lebih rendah, dan dapat memfilter suara lebih kecil seperti setiap per 1 millidetik sehingga suara yang dihasilkan dapat memberikan rata-rata error yang lebih rendah. Selanjutnya dapat dikembangkan kedalam sebuah aplikasi yang bekerja secara realtime.

\section{DAFTAR PUSTAKA}

[1] H. Kisumal. 2010, "Aplikasi Perintah Suara pada Windows," UINKJ, p. 12.

[2] P. Suharfin. 2018, "Perkembangan Teknologi dan Dampaknya Bagi Kehidupan Bermasyarakat," 27 Oktober, 2018. [Online]. Available: https://www.kompasiana.com/. [Accessed: 26-Nov-2019].

[3] Amalia Nurul. 2015, "Zaman yang Tidak Bisa Dihindari," 17 Juni, 2015. [Online]. Available: https://www.kompasiana.com, [Accessed: 26-Nov-2019].

[4] A. M. Harun Sujadi, Ii Sopiandi. 2017, "Sistem Pengolahan Suara Menggunakan Algoritma FFT (Fast Fourier Transform)," Pros. SINTAK, pp. 101-107. 
[5] D. A. Adi Rinaldi, Hendra. 2012, "Pengenalan Gender Melalui Suara dengan Algoritma Support Vector Machine (SVM)," STMIK GI MDP, No. 10, pp. 1-10.

[6] P. Kuncara. 2017, "Macam-macam Format File Audio Beserta Kelebihan dan Kekurangan," 28 Oktober, 2017. [Online]. Available: https://klikhost.com/macammacam-format-file-audio-beserta-kelebihan-dan-kekurangan/. [Accessed: 04-Dec-2019].

[7] H. R. Dodi Hasahatan, Muhammad Ihsan Zul. 2014, "Perancangan dan Implementasi Kinect Motion Capture Sensor untuk Interaksi dan Pembelajaran Tunawicara," J. Aksara Komput. Ter., Vol. 3, No. 1.

[8] M. M. Effendi, 2017, "Pengenalan Pengaruh Suara Konsonan Terhadap Vokal Dengan Nilai Koefisien Korelasi,” J. Pelita Teknol., Vol. 12, No. 4, pp. 35-41.

[9] S. A. Panggola, 2019, "Pengenalan Ucapan Menggunakan Python (Bagian 1 Bekerja Dengan Mikrofon)," 29 Desember, 2019. [Online]. Available: https://medium.com, [Accessed: 30-Aug-2020].

[10] idhearing, 2018, "Gangguan Pendengaran Frekuensi Tinggi," 08 Maret, 2018. [Online]. Available: https://www.pusatalatbantudengar.com, [Accessed: 30-Aug-2020].

[11] H. G. Koredianto Usman, Andriyan Bayu Suksmono, 2014, "Peningkatan Kinerja Skema Estimasi Arah Kedatangan Sinyal dengan Compressive Sensing Sparsitas Sudut dan Sampel Multisnap," INKOM, Vol. 8, No. 1.

[12] David, 2013, "Penerapan Algoritma Levenberg-Marquadt dan Backpropagation Neural Network Untuk Klasifikasi Suara Manusia,” J. Buana Inform., Vol. 4, No. 1, pp. 1-10.

[13] I. H. Desia Ilmina Suprapto, Koredianto Usman, 2008, “Desain dan Sintesis Arsitektur Hardware Ifft (Inverse Fast Fourier Transform) 64 Titik Berbasis Bahasa Pemrograman Vhdl," pp. 0-6.

[14] M. Retno Eka Pertiwi, Dr. Ir. Suhartati Agoes, 2017, "Implementasi Filter Finite Impulse Response Untuk Mereduksi Noise Pada Suara Menggunakan Metode Indowing," J. ELEKTRO, Vol. 10, No. 2, pp. 73-85.

[15] A. M. Andik Adi Suryanto, 2019, "Penerapan Metode Mean Absolute Error (Mea) Dalam Algoritma Regresi Linear Untuk Prediksi Produksi Padi," J. Sains dan Teknol., Vol. 11, No. 1, pp. 78-83.

[16] A. Muhardian. 2018, "Belajar Pemrograman Python Pengenalan Dasar Python dan Persiapan Awal," 15 September, 2018. [Online]. Available: https://www.petanikode.com, [Accessed: 29-Aug-2020]. 